\title{
RARE COMPLICATION DURING STELLATE GANGLION BLOCK A CASE REPORT*
}

Alfred T. C. Peng, M.D., Joanna Bufalo, M.D. and Louis S. BlanCato, M.D.

THE POSSIBIITY of an inadvertent injection of a local anaesthetic agent into the vertebral artery has been demonstrated by Moore. ${ }^{1} \mathrm{He}$ did this by the injection of a local anaesthetic and a radio-opaque dye into the vertebral artery under fluoroscopic visualization. Anatomically the vertebral artery is adjacent to the stellate

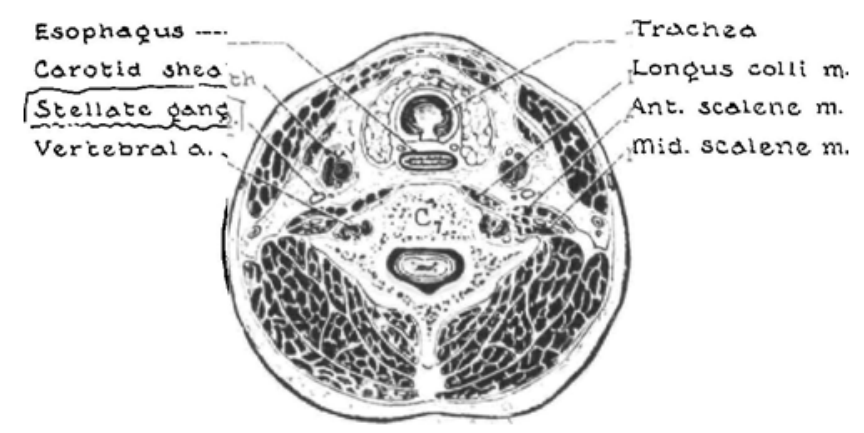

FIgure 1. Anatomically the vertebral artery is adjacent to the stellate ganglion. (From Moore, Daniel C., keGronal BLock, 2nd ed. (1958). Courtesy of Charles C. Thomas, Publisher, Springfield, Illinois.)

ganglion (Figure 1). Convulsion is one of the major toxic manifestations of a local anaesthetic agent following nerve block. It may be caused by overdose, intravenous injection, hypersensitivity, or an injection into an artery going to the central nervous system.

\section{CASE REPORT}

A 29-year-old white female was admitted because of sudden loss of hearing of four days duration. She denied any previous ear infection or dizziness. Vascular occlusion was suspected and she was treated with lipoflavenoid and nicotinic acid without improvement. A stellate ganglion block was requested by the Otolaryngology Service.

The patient was a well developed white female, weighing $110 \mathrm{lbs}$ and 5 feet 3 inches in height. All physical and neurological examinations were negative except a Weber test which showed impairment on the right side.

The patient was prepared for a right stellate ganglion block. The paratracheal approach was chosen. After careful aspiration of needle in all planes, a 1.5 per

'Department of Anesthesiology, St. Luke's Hospital Center.

Reprint Request to: 421 West 113th Street, New York, New York 10025.

Can. Anaes. Soc. J., vol. 17, no. 6, November 1970 
cent lidocaine was injected. The patient suddenly lost consciousness and developed twitching of various parts of the body followed by a seizure which lasted for approximately two minutes. Only $6 \mathrm{ml}$ of 1.5 per cent lidocaine ${ }^{*}$ had been injected at that time. The needle was immediately withdrawn and $\mathrm{O}_{2}$ administered via face mask manually. Without other therapy, the patient regained consciousness and no further convulsions were observed. There was no detectable evidence of a Horner's Syndrome. The procedure was discontinued and the medical treatment was resumed. In order to rule out an allergic reaction to lidocaine, an intradermal skin test was performed next day which was negative. ${ }^{2}$

\section{COMMENT}

This case demonstrates the rare occurrence of convulsion during a stellate ganglion block probably due to an inadvertent injection into the vertebral artery of the $90 \mathrm{mg}$ lidocaine ( $6 \mathrm{ml}$ of 1.5 per cent solution). On many occasions, this complication was ascribed to drug hypersensitivity or idiosyncrasy.

Lidocaine in doses of $100 \mathrm{mg}$ or more has been safely administered intravenously to the conscious patients for treatment of cardiac arrhythmia. ${ }^{3}$ However, convulsion may occur if more than $200 \mathrm{mg}$ of lidocaine was injected rapidly into the vein in conscious adults. ${ }^{4}$ Therefore, it is unlikely, that the convulsion noted in this patient was caused by an intravenous injection of $90 \mathrm{mg}$ lidocaine. We presume that the $90 \mathrm{mg}$ of lidocaine was delivered directly to the central nervous system via the vertebral artery. The arterial blood concentration of the drug injected would be equivalent to a patient who has received about $600 \mathrm{mg}$ lidocaine intravenously. (This is calculated on the basis that 15 per cent of cardiac output goes to the brain.) This arterial concentration is sufficient to cause convulsion in a majority of patients. It is important to note that careful aspiration of the needle cannot always prevent an intravascular injection because of the possibility of the ball valve action of the vessel wall against the bevel of the needle. Moore recommended that one or two $\mathrm{ml}$ of a local anaesthetic solution injected into the vertebral artery or carotid artery would, in most cases, cause the patient to complain of dizziness, a feeling of "blacking out", nausea, etc., and the alert physician would then aspirate for blood, check his landmarks, proceed carefully, and if signs and symptoms persist, temporarily discontinue the block. Thus, if after injection of $1 \mathrm{ml}$ of the 1.5 per cent lidocaine $(15 \mathrm{mg}$ ) we had waited for a few minutes to observe the subjective symptoms, this complication would have been avoided.

\section{RÉSUMÉ}

Une femme de 29 ans a présenté des convulsions au cours d'un bloc du ganglion étoilé pratiqué à la lidocaine pour le traitement d'une perte soudaine de l'ouie. On a soupçonné la possibilité d'une injection accidentelle dans l'artère vertébrale, puisque la dose totale de lidocaine ne fut que $90 \mathrm{mg}$. et que l'épreuve allergique était négative. La dose d'essai de $1 \mathrm{ml}$. de lidocaine à 1 pour cent antérieure au

'Lidocaine was in the ampoule, therefore no preservative (methylparaben) was added. 
block et injectée durant l'approche antérieure ou paratrachéale a aussi été invoquée.

\section{REFERENCES}

1. Moone, D. C. Stellate Ganglion Block. Springfield, Ill.: Charles C. Thomas (1954).

2. Aldrete, J. A. \& Johnson, D. A. Allergy to Local Anesthetics. J.A.M.A. 207: 356 (1969).

3. Gianelly, R.; von der Groeben, J. O.; Spivack, A. P.; \& Harrison, D. C. Effect of Lidocaine on Ventricular Arrhythmias in Patients with Coronary Disease. New Eng. J. of Med. 277: 1215-1219 (1967).

4. Steinhaus, J. E. Intravenous Local Anaesthetics, Int. Anaesth. Clin. 1: 639 (1963). 